\title{
Tulane
}

Tulane Economics Working Paper Series

\section{Losers distribution, with applications to financial inclusion: Lightning can strike twice, but it may not strike at all}

\author{
John H. Y. Edwards \\ Tulane University \\ edwards@tulane.edu
}

Working Paper 1905

April 2019

\begin{abstract}
This paper develops the "Losers distribution" a new discrete probability distribution that describes the number of losers in a k-player game with $n$-fold identical trials. The problem of financial inclusion demonstrates its application. Fair subsidized lotteries are proposed as a complement to microfinance for providing financing to the poor.

Keywords: Financial Exclusion, Inequality, Financial Market Failure, Income Distribution, Poverty, Lotteries

JEL codes: O1, C1, G1, H4,
\end{abstract}




\title{
Losers distribution, with applications to financial inclusion: Lightning can strike twice, but it may not strike at all
}

\author{
John H. Y. Edwards*
}

April 6, 2019

\begin{abstract}
This paper develops the "Losers distribution" a new discrete probability distribution that describes the number of losers in a k-player game with $n$-fold identical trials. The problem of financial inclusion demonstrates its application. Fair subsidized lotteries are proposed as a complement to microfinance for providing financing to the poor.
\end{abstract}

Keywords: Financial Exclusion, Inequality, Financial Market Failure, Income Distribution, Poverty, Lotteries

JEL codes: O1, C1, G1, H4,

\section{Introduction}

Many events arise that have a finite number of equally probable and mutually exclusive possible outcomes. Yet even after many trials not every possible outcome is expressed. Some may not occur even if the number of trials significantly exceeds the number of possible outcomes. One example is the repeated roll of a fair die. The frequency with which each side shows up after a given number of rolls is tallied. After 10 rolls no six or no four, or no six and no four turn up. A second example is a game of chance where a group of people each put some money into a pot. A game takes place and one winner takes the pot. The game is repeated a pre-determined number of times. Some players may never win, even if the number of games they play is fairly large. Example three involves a new, multi-unit housing development with identical homes that has just been put on the market. Prospective buyers are allowed to inspect a home of their choosing. After one week, some homes have been seen more than once and some may have not been visited at all.

These relations are all non-injective; more than one element of the domain of die rolls, games, and home visits can map onto the same outcome element in the codomains. But the more important property for the purposes of this paper is that the relations are also non-surjective - not every element in the codomain of outcomes (die-sides, game players, or houses) will necessarily be manifested. For ease of exposition, the set

\footnotetext{
${ }^{*}$ Corresponding Author. Department of Economics, Tulane University, 206 Tilton Hall, New Orleans, LA 70118; email: edwards@tulane.edu.
} 
of outcomes that are not manifested is called "the set of losers", or just "losers." The question addressed here is what is the expected number of losers when trials are identical and all outcomes are equally likely?

I introduce the "losers distribution," a new discrete probability distribution that describes the probability that after $\mathrm{n}$ identical trials there will be ' $l$ ' losers and ' $w$ ' winners We have $l+w=k$ - where ' $k$ ' is the number of players - and

$$
\sum_{i=1}^{n} w_{i}=n .
$$

The expected number of losers is calculated. The paper ends with an application to financial exclusion and a proposal to extend financing to the poor.

\subsection{MODEL}

A "lottery game" is a set $N$ of identical random draws ${ }^{1}$ with replacement that has cardinality $n=|N|$ and elements indexed by $i \in\{1,2, \ldots, n\}$. The elements of $\mathrm{N}$ are labeled. The lottery game is a function. To simplify the exposition and the transition to the application at this end of the paper, I will refer to the domain set of the game as "lotteries" and the co-domain as "players". A non-injective, non-surjective function maps the set of lotteries to the set of players. Without loss of generality, we can think of lottery draws as occurring sequentially with the index representing the order in which the lotteries take place. The co-domain consists of a set $K$ of lottery players with cardinality $k=|K|$, whose players are indexed by $j \in\{1,2, \ldots, k\}$. The players are labeled. The sample space of a game is thus $k^{n}$. For most of the discussion here it will be assumed that $n \geq k$.

Every lottery in an $n$-lottery game has $k$ outcomes, namely a win for some player $j$ and a loss for each of the remaining $(k-1)$ players. The outcomes of a single lottery can be represented by a $k x 1$ column vector with $(k-1)$ zeros representing the losers and the number one in position $j$ for the winner. The set of possible win vectors for a 5-person game are shown in Figure 1. For instance, the second 5-element column vector - with a 1 as its second element and zeros elsewhere -represents the outcome of a 5-person lottery draw where player 2 was the winner and player 1 and players 3 through 5 lost. If the probability of being drawn is not equal for all players, copies of the more likely columns can be added to this set to reflect the population from which unequal relative frequencies are drawn. For now however, I assume that the probability of being winning is $1 / n$, the same for all of the players. Figure 1 illustrates the collection of win-vectors that represent the 5 possible outcomes of a 5-player lottery. Alternatively this collection of vectors can be seen as the population from which lottery winners are randomly drawn when it is equally likely that any one player will be drawn. Columns 1 through 5 represent wins by players 1 through 5 , respectively.

\footnotetext{
${ }^{1}$ Some outcomes can be more likely than others. This context can be handeled within the framework developed here, but for the remainder of this paper it is assumed that the probability across outcomes is identical and equal to $\frac{1}{n}$
} 


\section{Figure 1: Possible Win Vectors for a 5-Person Game}

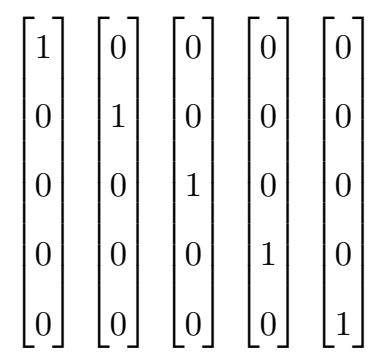

The collection of actual win-vectors can be arranged into a "win-matrix"' to represent the full set of outcomes from a game. The column sequence can represent the order in which wins took place. Figure 2 , represents a 5-player, 5-game lottery in which player 1 won the first and third draws, player 2 won the second and fourth draw, player 3 won the last draw, but players 4 and 5 each had zero wins.

\section{Figure 2: A Win Matrix: Player 1 and 2 win twice and player 3 wins the last game}

$$
\left[\begin{array}{lllll}
1 & 0 & 1 & 0 & 0 \\
0 & 1 & 0 & 1 & 0 \\
0 & 0 & 0 & 0 & 1 \\
0 & 0 & 0 & 0 & 0 \\
0 & 0 & 0 & 0 & 0
\end{array}\right]
$$

Each lottery in a game can be thought of as randomly selecting one column from Figure 2. The selected column is copied and then appended from left to right onto a new kxn win-matrix "W". Once the game concludes, the order of columns in $\mathrm{W}$ records the sequence of outcomes while the sum of each of the k rows gives the final tally of wins for players 1 through $k$. Thus post-multiplying $W$ by an $n x 1$ unit vector $U$, results in a $k x 1$ column vector $\mathbf{R}$ ' which is a tally of wins. The transpose of this vector $\mathbf{R}=\left(w_{1}, w_{2}, w_{3}, \ldots w_{k}\right)$ is a convenient way to represent the distribution of winnings from the game. Figure 3 illustrates one such tally for a 5 player, 9 lottery game in which player 1 won the first four times, player two won lotteries 5 and 6 , player 3 won the last 3 times. Players 4 and 5 lost every time. 
Figure 3: $k=5, n=9$

$$
\mathbf{W}_{5 \times 9} \times \mathbf{U}_{9 \times 1}=\mathbf{R}^{\prime}{ }_{5 \times 1}
$$

$$
\left[\begin{array}{lllllllll}
1 & 1 & 1 & 1 & 0 & 0 & 0 & 0 & 0 \\
0 & 0 & 0 & 0 & 1 & 1 & 0 & 0 & 0 \\
0 & 0 & 0 & 0 & 0 & 0 & 1 & 1 & 1 \\
0 & 0 & 0 & 0 & 0 & 0 & 0 & 0 & 0 \\
0 & 0 & 0 & 0 & 0 & 0 & 0 & 0 & 0
\end{array}\right]\left[\begin{array}{l}
1 \\
1 \\
1 \\
1 \\
1 \\
1 \\
1 \\
1 \\
1
\end{array}\right]=\left[\begin{array}{l}
\mathrm{w}_{1} \\
\mathrm{w}_{2} \\
\mathrm{w}_{3} \\
\mathrm{w}_{4} \\
\mathrm{w}_{5}
\end{array}\right]=\left[\begin{array}{l}
4 \\
2 \\
3 \\
0 \\
0
\end{array}\right]
$$

The distribution of winnings from the game can be more conveniently represented by the transpose of the right hand column vector $\mathbf{R}=(4,2,3,0,0$,$) . Commas have been inserted for clarity. Notice that while$ $\mathbf{R}$ conveniently tallies the wins, it loses all the information about the sequence of lotteries that produced them. In fact up to $n$ ! different arrangements of the columns in $\mathbf{W}$ can produce the same $\mathbf{R}$ vector.

We will return to this fact shortly, with more precision. For now, notice that $(4,2,3,0,0)$ is a partition of the number 9 . In fact, since $n$ and the $w_{i}$ are integers, with $w_{i} \leq n$ and

$$
\sum_{i=1}^{k} w_{i}=n
$$

every $\mathbf{R}$-vector describes a partition of the number $n$ into $k$ parts (counting zeros as parts). Partition theory typically ignores zeros -in what are called proper partitions -and treats the parts into which a number is divided as anonymous, indistinguishable, and interchangeable summands. Thus the $\mathbf{R}$-vectors $(4,2,3,0,0,0,0,0,0),(4,2,3,0,0),(0,2,3,4)$, and $(4,3,2)$ are the same partition of 9 into 3 parts.

So called proper partitions ignore zeros, and are conventionally ordered from their largest to smallest elements. For instance $(7,1,1),(6,2,1),(5,3,1),(5,2,2),(4,4,1),(4,3,2)$, and $(3,3,3)$ are the seven proper partitions of the number nine into 3 parts. In standard notation the number of partitions of $n$ into $w$ parts is written as $p(n, w)$, and the total number of partitions of the number $n$ as $p(n)$, where $p(n)=\sum_{i=1}^{k} p(n, w)$. So for instance there are 7 distinct partitions of the number 9 into 3 parts: $p(9,3)=7$ and there are altogether 30 partitions of the number 9: $p(9)=30$. The number of partitions grows very rapidly with $n$ : $p(3)=3, p(9)=30, p(20)=627, p(50)=204,226$, and $p(100)=190,569,292$ (sequence A000041). 
The theory of partitions is a well-developed subfield of number theory (for instance Andrews, 1984). But we must modify standard partition notation for our problem, because the arrangements of a partition matter, as do the zeros! In score-keeping for a lottery game, every ordering of a given proper partition represents a different allocation of the total $n$ wins among $w$ winners. For instance, the partition $(4,3,2)$ of the number 9 has $3 !=6$ versions that represent different allocations of a $4-3-2$ split of wins among three winners of a nine-lottery game. The number of allocations that are possible grows when losers are accounted for.

First consider the case where $n=k$ and every player wins at least one time, that is $w_{i}=1 \forall i \in$ $\{1,2, \ldots, w\}$. There are $n$ ! different draw sequences that can result in each player winning once, and yet all of these outcomes would be represented by the same $\mathbf{R}$-vector of ones. This is because $\mathbf{R}$-vector notation loses information on the sequence in which wins take place. This is a large number to ignore. In a 9-player, 9-lottery game there are $9 !=362,880$ different sequences that can lead to each player winning once. If all players win at least once and $n>k$, then some of the columns in the win-matrix $\mathbf{W}$ must be repeated for players who won more than once. An example of this can be visualized by ignoring the bottom two rows of zeros of the $\mathbf{W}$ matrix in Figure3, which then represents a 3-person, 9-fold lottery where nobody lost. To find the number of unique permutations of $\mathbf{W}$, the $n$ ! arrangements of columns must be divided by the product of the $w_{i}$ ! in order to account for identical columns. Thus the number of unique permutations of $\mathbf{W}$ is

$$
\frac{n !}{w_{1} !, w_{2} !, w_{3} !, \ldots, w_{k} !}
$$

which is of course a multinomial coefficient. Multinomial coefficients ignore the $\mathrm{l}=\mathrm{n}-\mathrm{w}$ losers, just as partition notation ignores zero summands. Since $0 !=1$, an arbitrary number of zero winners can be added without changing the result. The multinomial coefficient effectively counts the number different ways that a given distribution of wins - $\mathbf{R}$-vector - can be drawn among the subset of players who win at least once-the winners.

\subsection{THE LOSERS DISTRIBUTION}

The discussion to this point has laid out the reasoning and rationale behind each step in the construction of $L(l \mid n, k)$-the frequency with which $l$ losers will arise in a $k$-player, $n$-fold lottery game. Since the sample space is known to be to be $k^{n}$, it is straightforward to calculate the probability of these events as $\operatorname{Pr}(l \mid n, k)$

$=\frac{L(l \mid n, k)}{k^{n}}$. In the 9 - player, $9-$ fold lottery game example in Table 1 , we obtain $\operatorname{Pr}(9,3)=\frac{L(9,3)}{9^{9}} \approx 0.41$. The probability that 3 out of 9 players won't win anything at all is about $41 \%$.

Definitions: : Let $K$ be a set of players and $N$ be a set of lotteries, with cardinalities $k=\|K\|$ and $n=$ $\|N\|$, respectively. Index the elements of $K$ as $i \in\{1,2, \ldots, k\}$ and the elements of $N$ as $j \in\{1,2, \ldots, n\}$. A lottery game is a non-surjective, non-injective function with domain $N$ and codomain $K$ that assigns 
each lottery to one player. The assignments are called "wins". After the game, player $i$ has $w_{i}$ wins, with $n_{i} \geq 0 \forall i$ and $\sum_{i=1}^{w} w_{i}=n$. Define the player subset $\mathfrak{B}$ consisting of all players for whom $w_{i} \geq 1$. Players in $\mathfrak{B} \subseteq K$ are called "winners" and $\mathfrak{B}$ has cardinality $w=\|\mathfrak{B}\|$. Players with zero wins are "losers" and form the complement set $\mathfrak{E}$ with cardinality $\boldsymbol{l}=\|\mathfrak{E}\|$, so $\mathfrak{U} \cup \mathfrak{B}=K, \boldsymbol{l}+\boldsymbol{w}=n$, and $0 \leq \boldsymbol{l} \leq(k-1)$.

The tally of wins is arranged into a win vector $\mathbf{R}=\left(w_{1}, w_{2}, \ldots, w_{w}\right)$. When the losers are ignored and the $\mathbf{R}$-vector elements are arranged from largest to smallest, they form a proper $w$-fold partition of $n$. Let $\sigma_{n, w}$ designate one such $w$-fold partition of $n$ and $\mathfrak{\subseteq}_{n, w}$ the set of all $w$-fold partitions of $n$.

As we have seen, traditional partition notation arranges partition summands from largest to smallest, so that in $\mathbf{R}=\left(w_{1}, w_{2}, \ldots, w_{w}\right), i>j$ implies $w_{i} \geq \mathrm{w}_{j}$. For instance, one of the partitions of 9 into 6 parts would be written as $(2,2,2,1,1,1)$. When $n$ ! is divided by the factorials of all elements in a given $\sigma_{n, w}$, as in $M_{1}=\frac{n !}{\prod_{i=1}^{w} w_{i} !}$, the resulting quotient is the multinomial coefficient which counts the ways in which a particular $\sigma_{n, w}$ can arise as the win-vector of an $n$-fold lottery with $w$ players.

There is an alternative partition notation. $\mathbf{R}=\left(w_{1}^{r_{1}}, w_{2}^{r_{2}}, \ldots w_{m}^{r_{m}}\right)$. In this case the partition has $m$ distinct parts. Distinct $w_{i}$ are ordered from largest to smallest and the $r_{i}$ coefficients indicate how many times summand $w_{i}$ is repeated in the partition and should not be confused with exponents. Thus $\mathbf{R}=(2,2,2,1,1,1)$ can be written more succinctly in this alternative notation as $\mathbf{R}=\left(2^{3}, 1^{3}\right)$. This notation allows us to define a second multinomial coefficient as $M_{2}=\frac{w !}{\prod_{i=1}^{w} r_{i} !} \cdot M_{2}$ counts how many different ways a given $\mathbf{R}$-vector split can be arranged - thus treating the partition $(2,1,2,2,1,1)$ as different from $(2,2,2,1,1,1)$, because it has the same parts, but they are arranged in a different order.

The frequency with which a particular split arises — what in thermodynamics is called the "multiplicity" of a state -is $M_{1} \times \mathrm{M}_{2}$ - the product of these two multinomial coefficients.

$$
\operatorname{Freq}\left[\mathbf{R}\left(w_{1}, w_{2}, \ldots, w_{w}\right)\right]=M_{1} \times M_{2}=\frac{n !}{\prod_{i=1}^{w} w_{i} !} \frac{w !}{\prod_{i=1}^{m} r_{i} !}
$$

A result related to (2) is discussed in Faris (2011). Equation (2) gives all of the ways that $n$ labelled objects can be assigned to $w$ labelled sets in such a manner that none are empty. Kao and Zetterberg (1957) Theorem 2.2 proves that the number of multinomial coefficients that can be formed from the proper partitions of $n$ into $w$ parts is given by

$$
Q(n, w)=\sum_{\sigma_{n, w} \in \mathbb{S}} \frac{n !}{\prod_{i=1}^{w} w_{i} !}=\sum_{i=0}^{w-1}(-1)^{i}\left(\begin{array}{c}
w \\
i
\end{array}\right)(w-i)^{n} .
$$

$Q(n, w)$ counts all of the ways in which $n$ labeled objects can be assigned to $w$ labeled sets, such that no set is empty. This contrasts with Stirling numbers of the second kind, written as $S(n, w)$, which count all 
the ways in which $n$ labeled objects can be assigned to $w$ unlabeled sets:

$$
S(n, w)=\frac{1}{w !} \sum_{i=0}^{w-1}(-1)^{i}\left(\begin{array}{c}
w \\
i
\end{array}\right)(w-i)^{n}=\frac{1}{w !} Q(n, w) .
$$

Equations (3) and (4) show that $Q(n, w)$ numbers are related to Stirling numbers by a factor of $w !$.

We are now in a position to characterize the probability mass function of the losers distribution.

Theorem 1 Let $k, n \in \mathbb{Z}^{+}$and $n \leq k$. The probability of $l$ losers in a $k$-player, $n$-fold lottery game is given by

$$
\operatorname{Pr}(\boldsymbol{l} \mid n, k)=\frac{\left(\begin{array}{c}
k \\
l
\end{array}\right) \sum_{i=0}^{k-l-1}(-1)^{i}\left(\begin{array}{c}
k-l \\
i
\end{array}\right)(k-\boldsymbol{l}-i)^{n}}{k^{n}}
$$

Proof. Clearly $0 \leq \boldsymbol{l} \leq(k-1)$, so if there are $\boldsymbol{l}$ losers there are $w=k-\boldsymbol{l}$ winners. Winners distribute the $n$ wins among themselves in $w$ parts. These parts form a partition of $n$. Letting $\sigma_{n, w}$ represent one such $w$-fold proper partition of $n$ and $\mathfrak{\subseteq}_{n, w}$ represent the set of all proper $w$-fold partitions of $n$, from Kao and Zetterberg (1957) Theorem 2.2, we have that

$$
\sum_{\sigma_{n, w} \in \mathfrak{S}_{n, w}} \frac{n !}{\prod_{i=1}^{w} w_{i} !}=\sum_{i=0}^{w-1}(-1)^{i}\left(\begin{array}{c}
w \\
i
\end{array}\right)(w-i)^{n} .
$$

Equation(6) gives the frequency with which a $w$-fold split of the lotteries will occur, with $w$ players and every player winning at least once - it ignores the possibility that there might be one or more losers. But given any $w$-fold split of wins from a $k$-player, $n$-lottery game, $\boldsymbol{l}$ zeros can be added to the win-vector $\mathbf{R}$ in $\left(\begin{array}{c}w+l \\ l\end{array}\right)$ ways. The frequency with which a $w$-fold split will occur in a $k$-person, $n$-lottery game - and thus the frequency with which there will be $\boldsymbol{l}$ losers is therefore

$$
\left(\begin{array}{l}
k \\
l
\end{array}\right) \sum_{\sigma_{n, w} \in \mathfrak{S}} \frac{n !}{\prod_{i=1}^{w} w_{i} !}=\left(\begin{array}{l}
k \\
l
\end{array}\right) \sum_{i=0}^{w-1}(-1)^{i}\left(\begin{array}{c}
w \\
i
\end{array}\right)(w-i)^{n} .
$$

Letting $w=k-\boldsymbol{l}$ and dividing the frequency by the sample space gives the probability of $\boldsymbol{l}$ losers $\operatorname{Pr}(\boldsymbol{l} \mid n, k)$ $=\frac{\left(\begin{array}{l}k \\ l\end{array}\right) \sum_{i=0}^{k-l-1}(-1)^{i}\left(\begin{array}{c}k-l \\ i\end{array}\right)(k-l-i)^{n}}{k^{n}}$, as in Equation 5 .

Corollary 1: The expected number of losers in a $k$-player, $n$-fold, lottery game is given by

$$
\hat{l}=E(\boldsymbol{l})=\frac{\sum_{l=0}^{k-1} \boldsymbol{l} L(\boldsymbol{l})}{k^{n}}
$$




\subsection{Recursive Relations}

There is a recursive relation between the $Q(n, w)$.

Theorem 2: Let $Q(n, w)$ indicate the sum of all multinomial coefficients generated by the proper partition of $\mathrm{n}$ into $\mathrm{w}$ parts. There exists a recursive relation of the form

$$
Q(n, w)=w\{Q[(n-1),(w-1)]+Q[(n-1), w]\}
$$

Proof. From equation (3) we have that the term in brackets in (7) becomes $Q[(n-1),(w-1)]+Q[(n-1), w]$ $=\sum_{i=0}^{w-1}(-1)^{i}\left(\begin{array}{c}w \\ i\end{array}\right)(w-i)^{n-1}+\sum_{i=0}^{w-2}(-1)^{i}\left(\begin{array}{c}w-1 \\ i\end{array}\right)(w-1-i)^{n-1}$

The first term can be rewritten to obtain $\left(\begin{array}{c}w \\ 0\end{array}\right) w^{n-1}+\sum_{i=1}^{w-1}(-1)^{i}\left(\begin{array}{c}w \\ i\end{array}\right)(w-i)^{n-1}+\sum_{i=0}^{w-2}(-1)^{i}\left(\begin{array}{c}w-1 \\ i\end{array}\right)(w-1-i)^{n-1}$

$=w^{n}+\sum_{i=1}^{w-1}(-1)^{i}\left(\begin{array}{c}w \\ i\end{array}\right)(w-i)^{n-1}-\sum_{i=1}^{w-1}(-1)^{i}\left(\begin{array}{c}w-1 \\ i-1\end{array}\right)(w-i)^{n-1}$.

The sign change for the third term in the last equation comes from changing its limits of summation. Collecting terms and making use of the Pascal triangle identity $\left(\begin{array}{c}w \\ i\end{array}\right)=\left(\begin{array}{c}w-1 \\ i\end{array}\right)+\left(\begin{array}{c}w-1 \\ i-1\end{array}\right)$, this becomes

$$
\begin{gathered}
w^{n}+\sum_{i=1}^{w-1}(-1)^{i}\left(\begin{array}{c}
w-1 \\
i
\end{array}\right)(w-i)^{n-1} \\
=\sum_{i=0}^{w-1}(-1)^{i}\left(\begin{array}{c}
w-1 \\
i
\end{array}\right)(w-i)^{n-1} \\
=\sum_{i=0}^{w-1}(-1)^{i}\left(\begin{array}{c}
w-1 \\
i
\end{array}\right) \frac{(w-i)^{n}}{(w-1)}
\end{gathered}
$$

When this last expression is multiplied by $w$, we obtain

$$
\begin{array}{r}
\{Q[(n-1),(w-1)]+Q[(n-1), w]\} w=\left\{\sum_{i=0}^{w-1}(-1)^{i}\left(\begin{array}{c}
w-1 \\
i
\end{array}\right) \frac{(w-i)^{n}}{(w-1)}\right\} w \\
=\sum_{i=0}^{w-1}(-1)^{i}\left(\begin{array}{c}
w \\
i
\end{array}\right)(w-i)^{n}=Q(n, w),
\end{array}
$$

the desired result.

Comments. The recursive nature of $Q(n, w)$ lends itself to the construction of a $Q$-triangle, shown in Table 4, that is analogous to Pascal's triangle. Alternatively, the $Q$-triangle can be derived as a series of Hadamard, or entrywise matrix products. A sequence of lower triangular matrices (with the upper triangles of zeros omitted) appears in Tables 2 through 6. Entries of the matrix in Table 2 are Stirling numbers of 
the second kind, $S(n, w)$ — series A008277. They count the ways in which $n$ distinguishable, or "labeled" elements of objects can be assigned to $w$ indistinguishable, or "unlabeled" sets. Stirling matrix row sums $\sum_{w=1}^{n} S(n, w)$ yield the Bell numbers — series A000110.

Table 3 contains the permutations $w_{i}$ ! for $w_{i} \leq n$. As Equation (3) makes clear, the $Q$-Triangle entries $Q(n, w)$ of Table 4 can be derived as $w ! S(n, w)$. So, letting $\mathfrak{R}_{i}$ stand for the lower-triangular matrix in Table "i", the elements of Table 4 are obtained as $\mathfrak{M}_{2} \diamond \mathfrak{R}_{3}=\mathfrak{R}_{4}$, where $\diamond$ stands fortheHadamardproduct.Theelementsinrown, colum form the $Q$-triangle, the sum of all multinomial coefficients that can be generated from a proper partition of $n$ into $w$ parts. The row sums of this matrix are given by

$$
T \sum_{w=1}^{n} Q(n, w)=\sum_{w=1}^{n} w ! S(n, w)
$$

and generate the Fubini numbers — series A000670, also known as the ordered Bell numbers. Table 5 lists the left-justified, binomial coefficient values of Pascal's triangle - omitting the first column of $n 0 \mid=1$ values.- these have rows which sum to Gaussian binomial coefficients. Finally, Table 6, shows the "Losers distribution" matrix. It consists of a lower-diagonal matrix whose elements are the Hadamard product of corresponding $Q$-matrix elements of Table 4 and binomial coefficients from the Pascal triangle (shown in Table 5): $\mathfrak{M}_{6}=\mathfrak{R}_{4} \diamond \mathfrak{R}_{5}$, or equivalently $\mathfrak{R}_{6}=\mathfrak{R}_{2} \diamond \mathfrak{M}_{3} \diamond \mathfrak{R}_{5}$. Table 6 rows sum to $n^{n}$, the sample space.

\section{APPLICATION TO FINANCIAL INCLUSION}

It is well known that the poor are less likely to participate in formal financial markets (Morduch, 1999). In times of economic shock or when faced with short-term cash flow problems the poor typically turn to informal sources of finance, including friends and family, pawn shops, moneylenders, and loan sharks. The last two decades have seen a surge of creativity and financial resources invested in developing more structured and less usurious ways for "financial inclusion" in formal credit markets such as organizing credit cooperatives and rotating savings and credit associations (Armendáriz de Aghion and Murdoch, 2005). The work of Muhammad Yunus in Bangladesh is one of the earliest and the best known efforts to formally address this unmet demand of the poor by building social capital among small groups of borrowers. Grameen Bank's "micro-finance" scheme met with great early success and acclaim, earned Yunus a Nobel Peace Prize, and spun off many emulators. However recent assessments have been less sanguine about the mechanisms behind success of Grameen Bank lending (Jain, 1996), about the long term benefits of micro-lending in general (Banerjee, Duflo, Glennerster, and Kinnan, 2015 and Banerjee, Karlan, and Zinman, 2015), raised the possibility of market power (Bairagi et al., 2014), and even cautioned that microfinance coverage expansion may be a primrose 
path leading to large scale collapse of the formal banking sector (Polgreen and Vajaj, 2010). The problem is that the constraints on informal lending are ultimately the same ones that are faced by formal sector lending.

Financial exclusion is not confined to developing countries. It is a concern in well-developed financial markets too and contributed to the creation of the Consumer Financial Protection Bureau (CFPB) in the U.S. through the Dodd-Frank Wall Street Reform and Consumer Protection Act of 2010. In 2016, the CFPB conducted a "Financial Wellbeing Survey", one of the first of its kind. This 217-question, nationally representative survey of 6,394 adults confirms that a large segment of the U.S. population is unserved by formal financial markets. About $22 \%$ of respondents report that they had applied for credit in the previous year and were turned down, or did not apply because they thought that they would be turned down. Yet, when asked if in times of hardship they have friends or family who would lend them money and expect repayment, 39\% of American adults replied "no". When asked if family or friends would lend them money without expecting repayment, $68 \%$ said "no". About $4.5 \%$ used payday loans, cash advance loans, or pawn shops to obtain loans ${ }^{2}$. A large fraction of the American is excluded from the financial market.

Campbell et al. (2011) report that payday loans charge interest in the range of 15 to $30 \%$ per week and that the loans are small — with $80 \%$ below $\$ 300$. Lawrence and Elliehausen (2008) find that payday loan borrowers tend to be less educated, younger, less likely to own a home, and have poor credit ratings $-73 \%$ have been turned down for formal credit within the past 5 years, compared to the national average of $21.8 \%$ of all adults.

The reason for exclusion explored in this section is voluntary self-exclusion from formal financial markets. Voluntary self-exclusion arises when a person is unwilling to participate in formal financial market at the interest rates that they face. Transactions costs, risk, and asymmetric information create a spread between the formal market rate of interest that a person is charged for borrowing and the rates she is paid for saving. Furthermore, this gap varies across the population in a systematic manner. The spread tends to be higher for people with less wealth, for the young, and for ethnic minorities. A large gap between high interest charged for borrowing and low interest paid on savings in formal markets makes alternative, informal financial arrangements attractive. These alternatives are not attractive in their own right, they are attractive in comparison to the best formal market opportunities.

Ethnic discrimination, transactions costs, costs associated with evaluating moral hazard, costs of acquiring information on ability and default risk, non-competitive market structures - these are all factors which

\footnotetext{
${ }^{2}$ Figures are the author's calculations, based on the CFPB survey.
} 
widen the spread between rates of interest on borrowing and lending. The spread will be higher for the poor and especially for poor minorities. The poor face a wider spread between the rate of interest that they must pay for formal borrowing and the rate that they can earn on formal savings.

Informal lending mechanisms compete with formal ones by finding niches that formal financial institutions do not exploit. Friends and family may have more information about a borrower and can encourage repayment by resorting to social suasion that is unavailable to banks. Payday lenders are able to loan small amounts by securing the borrower's next paycheck - something banks do not traditionally do. Pawnshops accept and store high-value, relatively liquid durable goods as collateral for loans that are a fraction of the expected sale value of these goods. NGO-supported micro finance groups seek to collect better information on the borrowers than is available to commercial banks and often try to build social capital that can be used for social suasion.

Such mechanisms notwithstanding, the spread of informal lending mechanisms among the poor is ultimately constrained by the same difficulties that limit formal financing: fixed transactions costs, a lack of $a$ priori information on creditworthiness, and no collateral in the event of default. Most of the world's poor remain financially excluded ADD MORE SOURCES... The challenge is to develop a mechanism that allows all of the poor to benefit from pooling their financial resources in the same way that wealthy people do. "The challenge remains to find ways to deliver small loans and collect small deposits while not sending fees and interest rates through the roof. And if that objective cannot be met, the challenge is to develop a framework for thinking about microfinance as a social tool that might need to rely, to some degree and in some places, on continuing subsidies." (Armendáriz, 2010, 318)

\section{Lotteries as Financial Instruments for the Poor}

\subsection{Fair Lottery Clubs}

In this section I explore the use of frequent fair lotteries with small prizes to bridge the financial gap. A fair lottery is defined as a lottery where the ticket price is equal to the expected value of the prize. Letting $z$ be the ticket price, $Z$ the lottery prize and $p$ the probability of winning, a lottery is fair when

$$
z=E(Z)=p Z
$$

The reasoning behind proposing fair lotteries as a bridge to financial inclusion is based on how the formal 
alternatives are for the financially excluded. When viewed in isolation widespread participation in games of chance with even odds is difficult to reconcile with rational, fully informed, risk-neutral behavior. But when compared to financial markets with a very high interest spread, fair lotteries can look like attractive alternative financial instruments. If individual time preference rates fall between the interest rate spread, a risk-neutral would be borrower will prefer inter-temporal games with a zero expected present value to formal financial markets. As the interest rate spread widens, more risk-averse borrowers will be attracted. Since lack of collateral, high information costs, short earnings-histories, ethnic and class discrimination all tranlate into a higher spread, it is more likely that the poor, the young, and women and minorities who face discrimination in formal financial institutions will prefer the fair lottery. The attraction is likely to be greatest for recent migrants, ethnic minorities, and for the young, the groups that account disproportionately for the urban poor in developed and developing countries alike.

I begin by ignoring default risk and transactions costs. Everybody is identical and assumed to be honest and to be able to meet their payment obligations. Consider a financial market in which the interest rate on savings is zero and the rate charged for borrowing is $i>\delta$ a, where $\delta$ is the individual time preference rate. In such a world, a club built around a lottery game can generate significant welfare gains for all but one of its members - and he will be no worse off. A lottery club is formed at time zero when $n$ people agree to play a game that has the following rules. The game will consist of $n$ identical fair lotteries spaced over equal time intervals of duration $\mathrm{t}$, for a total game duration of $T=n t$. Before every lottery, each member contributes $\$ z$ to create a total prize of $\$ Z=n \$ z$. When the first game takes place at time $t$, all member names are placed in a bin and one name is drawn at random. The winner is given the prize of $\$ Z$. At time $2 t$ the second lottery takes place in a manner that is identical to the first one, except that there are now $(n-1)$ names to draw from, because the first winner's name has been removed (no replacement). At time $3 t$ the third lottery is played with $(n-2)$ member names in the bin. This is repeated $n$ times, until all $n$ participants have "won" $\$ Z$.

It is easy to show that any risk-neutral person with a positive discount rate will prefer to join a lottery club - a priori - - to saving in any financial market that has an interest rate split which spans their discount rate. Similarly, given any degree of risk-aversion, there exists a market interest rate spread such that lottery club membership will be preferred. Therefore, if (a) people have a positive discount rate, (b) they are risk-averse, and (c) the formal financial market interest rate split is a decreasing function of wealth, poorer people will self-select into the lottery clubs. Notice also that a weakly risk-averse person has no incentive to join a club unless she is financially constrained. What proportion of the population will choose to join a lottery club depends on the distribution of income, the distribution of risk-aversion, and on the size of the 
interest rate split that they face in formal financial markets. A posteriori the first $(n-1)$ club members to receive a payout will better off having joined in the lottery game than if they had saved at zero interest and the $n^{\text {th }}$ player will be indifferent. The lottery game therefore generates a Pareto improvement. Such social gains will be especially large in markets with high rates on borrowing and non-positive interest rates paid on formal savings accounts - a financial environment that is all too familiar to the poor throughout the world. The break-even constraint implied by fairness rules out private provision. So -in the absence of default risk -it can be argued that fair lottery clubs are public goods.

\subsection{Fair, Open Lotteries}

Default risk creates a fatal problem for lottery clubs. Once a member has received her prize, she will want to quit. She has no incentive to return to the game and continue making payments. If early winners default, later prizes will be less than $\$ Z$, the odds of winning the lottery will no longer be fair, and the club will fall apart. This default risk can be overcome - at a cost.

Consider a fair lottery which pays $\$ Z$ with probability $p$ and charges $z$ per ticket, with $z=p Z$, as before. However now allow the lotteries to be open. No club membership is required. Anybody can play and they can play whenever they want to and for as long as they want to. Identical lotteries are held every $t$ intervals of time forever and $Z$ is set to be small -say at some fraction of the local poverty line or as a multiple of the local minimum monthly wage. The probability of winning, $p$, is large. For instance $t$ and $p$ can be set so that $\frac{t}{p}$ is approximately equal to one year. If the lottery is held every week, then $p=\frac{1}{52}$.

The reasoning for lottery clubs carries through to the open lottery. Risk-neutral people will prefer the open lottery to participation in financial markets if the formal interest rate split spans their time preference rate and if they are financially constrained. Therefore, the poor will self-select into the market for lottery tickets. In fact exactly the same number will want to participate in an open lottery as would join lottery clubs if clubs were offered instead. Also, for any given level of risk aversion, there exists a formal market interest rate spread such that participation in the open lottery will be preferred. But, because a fair open lottery can not generate profits, it will have to be publicly provided. Fairness and private provision are not compatible.

However, - in contrast to the lottery clubs - open fair lotteries will generate Pareto improvements only in the a priori sense. The utility of people who wish to play will rise when the lottery is made available and no one's utility will fall - this is revealed by the decisions to buy tickets. 
The ex post situation is more complicated. If a risk-neutral person with a positive time preference rate plays the lottery every time it is offered for $T$ periods, will he say that he is better off having played? Or will he say that he wishes he had saved the ticket money instead? His answer will depend on whether, when, and how many times he won. If he played every period, for $n=\frac{1}{p}$ times and he won at least once at a time $t^{*}<T$, he will be better off having played the lottery and will not wish he had saved instead. If he won more than once he will be happy. If he won only once and his win took place in period $\mathrm{T}$ he will be indifferent. If he lost $\mathrm{n}$ consecutive times, he will wish he had saved instead.

Next, consider selecting a group of $n$ people who chose to play the open lottery $n$ consecutive times, such that each player won once and no two players won in the same period. Thus the group would have one winner for each of the $n$ lottery dates and the collective outcome for this group would be exactly the same as for the lottery club in a perfect world. How many such groups could be formed out of the population that chose to participate in the open lottery?

Once all such groups have been drawn from the full set of players, the remainder will consist of players who won more than once and players who lost every time. ${ }^{3}$ Though fair a priori, the lottery will almost surely result in a transfer from losers to winners. Those who win at least once will be glad that they played, and those who lose every time will wish that they had saved their money instead. This fact is at the root of objections to publicly-sponsored lotteries, even if they are fair.

\subsection{Compensated Open Lottery}

Now consider a compensated open lottery. It has all of the same conditions as the open lottery described before - the lottery is fair, anyone can play, they can play as many times as they wish, and they have no obligation to continue playing. However, now any player who can prove that she has had n-consecutive losses will have her money returned to her. Every win resets the clock. Because the lottery is fair, $100 \%$ of the revenues from ticket sales must go to paying prizes. Therefore the money for compensation payments to the losers has to be subsidized. Since some players are likely to win more than once, the amount of the subsidy needed to compensate the n-time losers will depend on the proportion of players who lose $\mathrm{n}$ consecutive times. This proportion is stochastic and is in fact the random variable described by the losers distribution in the first section of the paper.

The lower bound on the share of prize money that would have to be subsidized occurs when all players

\footnotetext{
${ }^{3}$ The average number of wins in this group will be one.
} 
play $n$ times -they continue to play the lottery after winning. If $N^{*}$ people decide to play the open lottery and $N^{*} \gg n$, the proportion of losers among the $\mathrm{N}^{*}$ will converge to the mean of the losers distribution for an $n$-person, $n$-fold lottery.

The number of people who would have to be compensated then depends on the expected number of losers $l$ in Equation(8). The lower bound on the share of prize money that will have to come from a subsidy is thus /openequation

$$
s_{L}=\frac{\hat{l}}{n}
$$

Figure 1 shows that $s_{L}$ converges to about $37 \%$ for large values of $n$ and lies between 35 and $36 \%$ for values of that would be used in practice.

The upper bound for the subsidy emerges from the worst case scenario where all winners "default" — that is, players continue to buy tickets only until their first win. In this version of the world $n$ tickets are sold for the first drawing at a price of $z$ each, $(n-1)$ for the second one, $(n-2)$ for the third one, and so forth. After the last draw, ticket revenues of $\frac{(n+1) n z}{2}$ will have been gathered, but $n^{2} z$ will have been paid in prize money. The upper bound $s_{u}$ on the share of the prize money that will be have to be subsided is given by

$$
s_{U}=\frac{n-1}{2 n}
$$

which converges to $50 \%$ as $n$ goes to infinity.

The lottery authority can control the amount of the subsidy by limiting the number of tickets sold and requiring proof of $\mathrm{n}+$ consecutive losses before a prize is awarded to a loser, with $\geq 1$. Figure 3 illustrates how the distribution of losers for a $k=10$ lottery shifts rapidly to the left as $n$ rises from 10 to 16 . Over this range, the lower limit $s_{L}$ falls from $34.9 \%$ (for $\left.n=10\right)$ to $28.2 \%(n=12), 22.9 \%(n=14)$, and $18.5 \%(n=16)$.

When the open lottery is offered every $t$ periods in perpetuity, the proportion of the subsidy is likely to be closer to the lower bound. After an initial burst from pent-up demand, new financial needs will arise continuously just as they do in formal financial markets, creating a more or less steady flow of demand for lottery tickets. Governments can control the size of the lottery budget by limiting the number of tickets that are sold to some multiple of $\mathrm{n}$. The variance in the expected number of losers is small and falls with $n$. Figure 4 shows that with $n=50$, the expected number of losers is 18.2 and the standard deviation is 2.2 .

Desirable values for $n$ are likely to be quite small -weekly drawings for example. If $n=50$ and $g=$ 0 , the expected subsidy would be bracketed by $s_{L}=36.4 \%$ and $s^{U}=49.0 \%$. Seen another way, every $\$ 100$ of government financing generates between $\$ 204$ and $\$ 278$ in savings among the poor. There is no roll for 
collateral, information asymmetry, default risk, or gender, racial and ethnic discrimination.

\subsection{Lotteries Compared to Microfinance}

How would a subsidized fair lottery compare to microfinance mechanisms that mushroomed over the past few decades? Microfinance has undoubtedly created a source of financing for a very large number of people who could not -or chose not to -participate in formal financial markets. By the end of 2013 there were 3,098 microfinance institutions lending to over 211 million borrowers (Microcredit Summit Campaign, 2016). Yet these organizations are typically dependent on overt and hidden subsidies, charge high interest rates, and are plagued by default. Lafourcade et al. (2006) analyzed 163 microfinance organizations in 11 African countries and found that only $47 \%$ earned positive returns -returns are typically based on calculations that count subsidies as revenue. So "the reality is that much of the microfinance movement continues to take advantage of subsidies" (Armendáriz and Morduch, 2010, p. 318).

In a very thorough recent study Cull, Morduch, and Demirgüç-Kunt (2018) analyze proprietary data on 1,335 microfinance institutions that serve over 80 million borrowers globally. They find that "subsidy remains pervasive," averaging $13 \%$ per dollar spent on loans and that this rate is highly skewed. Despite having existed for about half a century now, apparently no way has yet been found to fully integrate microfinance for the poor into formal financial markets. Microfinance markets remain segmented, with NGO's accounting for the bulk of the smallest loans, formal banks accounting most larger "microloans" -median loans 7 times larger than the NGO's - and non-bank financial institutions (NBFIs) covering the middle ground. They also find that lending costs are very similar across NGO's, NBFIs, and formal banks and that fixed costs dominate the cost of lending. Lending costs are therefore relatively 'flat' with respect to loan size and the result that cost per loan is higher for the NGO's because they specialize in granting smaller loans. The most troubling finding of Cull, Morduch, and Demirgüç-Kunt (2018) is that - as a result of higher costs — "the poorest customers in the microcredit sector pay the highest interest rates." The average rate charged to the poorest customers ranges from 30 to $40 \%$.

Banerjee, Karlan, and Zinman (2015) review some of the first causal studies of microfinance programs. They review 7 programs in Bosnia, Ethiopia, India, Mexico, Mongolia, and Morocco and find evidence of only modest impact. Though explicitly seeking to address financial exclusion all 7 programs that are evaluated placed severe restrictions on borrower eligibility. These include

- Bosnia: microentrepreneurs posessing sufficient collateral, repayment capacity, credit worthiness, business capacity, and credit history; $22 \%$ APR interest. 
- Ethiopia: microentrepreneurs, joint group liability, proof of poverty status, posessing sufficient collateral, and evidence of a viable business plan; $12 \%$ APR interest.

- India: female, joint group liability, home ownership, local residence for at least 3 years; $24 \%$ APR interest.

- Mexico: female, microentrepreneurs, proof of business ownership or significant economic activity, group liability; $110 \%$ APR interest.

- Mongolia: female, microentrepreneurs, group liability; $26.8 \%$ APR interest.

- Morocco: microentrepreneurs, proof of economic activity for at least 12 months, group liability; $14.5 \%$ APR interest.

\section{EXPAND DISCUSSION}

Banerjee, Karlan, and Zinman (2015) report low take-up rates in the 5 studies that used randomized program placement. They also find some evidence that pre-microcredit formal and informal financing is crowded out by these programs. Both the low take-up and crowding out undoubtedly have something to do with these eligibility restrictions.

\subsection{Conclusions}

This paper has developed a new probability distribution, the "Losers Distribution"' and demonstrated its application to the problem of financial exclusion.

Can open fair lotteries do a better job of extending financial inclusion to the poor? The arguments developed here suggest that they may be able to. They self-target the poor, eliminate the need for screening of any sort, and create a Pareto improvement in the ex-ante sense that those who choose to participate are by definition people who prefer a chance at obtaining a lump sum of cash early to the certainty of having to wait for it.

However, even fair open lotteries randomly redistribute resources. They do not generate Pareto improvements in the ex post sense and the pre-lottery distribution of income first order stochastically dominates the post-lottery distribution and therefore will worsen poverty as defined by a wide class of poverty measures (Atkinson, 1987). 
A fair lottery which compensates losers will restore ex-post Pareto dominance defined over the set of lottery participants. And, while the estimated $34 \%$ lottery subsidy rate is high, it is within the bounds of the subsidies that are currently sustaining microcredit institutions world-wide. At the same time, compensated lotteries should do a much better job of reaching the poorest, most financially excluded segments of the population. When compared to the microcredit initiatives that have been tested, the administrative costs of a compensated fair lottery would likely be far lower, and subsidies would be completely transparent. Take up rates should be much higher.

Finally, the transition from a pre to a post-compensated lottery national income distribution satisfies the Pigou-Dalton transfer principle if lottery subsidies are financed with revenues raised from an income tax with a zero rate bracket for people below the poverty line and only the poor self-select into the lottery.

Fair lotteries are unlikely to replace microfinance and will certainly not replace formal banking, — they are not intended to. There is a special place for them in financial markets as a the missing link to the financially excluded poor.

\section{References}

Andrews, George E. 1984. The theory of partitions, New York, Cambridge Mathematical Library.

Armendáriz de Aghion, B., Morduch, J. 2010. The Economics of Microfinance, 2nd edition, Cambridge, Mass: MIT Press.

Atkinson, A.B. 1987. "On the measurement of poverty." Econometrica, 55 (4): 749-764.

Campbell, John Y., Howell E. Jackson, Brigitte C. Madrian, and Peter Tufano. 2011. "Consumer Financial Protection." Journal of Economic Perspectives 25 (1): 91-114.

Chetty, Raj. 2006. "A New Method of Estimating Risk Aversion." American Economic Review, 96 (5): 1821-1834. DOI: 10.1257/aer.96.5.1821

BBC News. October 4, 2018. Italian 'Robin Hood' banker sentenced over $1 \mathrm{~m}$ pilfered for the poor. Retrieved from https://www.bbc.com/news/world-europe-45745082

Consumer Financial Protection Bureau. 2013. Financial Literacy Annual Report.

Cull, Robert, Jonathan Morduch, and Asli Demirgüç-Kunt. 2018. "The Microfinance Business Model: Enduring Subsidy and Modest Profit." World Bank Economic Review. forthcoming. 
Faris, W. G. 2011. "Multinomial coefficients: Notes from Math 447-547 lectures", University of Arizona. Retrieved from http://math.arizona.edu/ faris/combinatoricsweb/multinomial.pdf

Feller, W. 1957. An introduction to probability theory and its applications. New York, Wiley.

Guillen, M. and Tschoegl, A. 2002. "Banking on Gambling: Banks and Lottery-Linked Deposit Accounts," Journal of Financial Services Research Vol. 21, No. 3.

Kao, R. C. and L. H. Zetterberg 1957. "An identity for the sum of multinomial coefficients", The American Mathematical Monthly 64:2, 96-100.

Lafourcade, Anne-Lucie, Jennifer Isern, Patricia Mwangi, and Matthew Brown. 2006. "Overview of the Outreach and Financial Performance of Microfinance Institutions in Africa." Microbanking Bulletin, 12, April, 3-14.

Lawrence, Edward C., and Gregory Elliehausen. 2008. "A Comparative Analysis of Payday Loan Customers." Contemporary Economic Policy, 262.:299-316.

Microcredit Summit Campaign February, 2016. State of the campaign report 2015. Retrieved from https://stateofthecampaign.org/data-reported/

Morduch, Jonathan. 1999. "The Microfinance Promise." Journal of Economic Literature 37 (4): 15691614 .

Polgreen, Lydia, and Vikas Bajaj. 2010. "India Microcredit Faces Collapse From Defaults." New York Times, November 17. https://www.nytimes.com/2010/11/18/world/asia/18micro.html

Zeelenberg, M., Pieters, R. 2004. Consequences of regret aversion in real life: The case of the Dutch postcode lottery. Organizational Behavior and Human Decision Processes 93, 155-168. 


\begin{tabular}{|c|c|c|c|c|c|c|c|c|c|}
\hline \multicolumn{10}{|c|}{ TABLE 1} \\
\hline 1 & $\underline{2}$ & $\underline{3}$ & $\underline{4}$ & $\underline{5}$ & $\underline{6}$ & $\underline{7}$ & $\underline{8}$ & $\underline{9}$ & $\underline{10}$ \\
\hline $\begin{array}{c}\text { \# of } \\
\text { winners } \\
\text { "w" }\end{array}$ & $\begin{array}{c}\text { Unique partitions of } \\
\text { the number } 9 \text { or " } R \text { - } \\
\text { Vectors" }\end{array}$ & $\begin{array}{c}p(9, w): \# \\
\text { of } \\
\text { partitions } \\
\text { of } 9 \text { into } \\
w \text { parts }\end{array}$ & $\begin{array}{c}\text { \# of ways in } \\
\text { which this Win } \\
\text { Vector Exactly } \\
\text { can occur } \\
\text { (multinomial } \\
\text { coefficient of R- } \\
\text { vector) }\end{array}$ & $\begin{array}{c}\text { Combinat } \\
\text { ions of } \\
\text { "w" } \\
\text { winners } \\
\text { with this } \\
\text { vector }\end{array}$ & $\begin{array}{c}\mathrm{Q}\left(9, \mathrm{X}_{i}\right): \\
\text { Prob. Of This } \\
\text { Win Vector } \\
\text { for any } \\
\text { Winner }(\text { Col.4 } \\
\text { x Col.5) }\end{array}$ & $\begin{array}{c}\sum \mathrm{Q}\left(9, w_{\mathrm{j}}\right) \\
\mathrm{Q} \text {-Triangle } \\
\text { Entries }\end{array}$ & $\begin{array}{c}\text { Binomial } \\
\text { Coefficients: } \\
\text { Pascal's } \\
\text { triangle } \\
\text { entries }\end{array}$ & $\begin{array}{c}L\left(9, w_{j}\right): \\
\text { Prob. Of This } \\
\text { Win Vector for } \\
\text { any Winner } \\
\text { (Col.6 x Col.8) }\end{array}$ & $\begin{array}{c}\sum \mathrm{L}\left(9, w_{\mathrm{j}}\right)= \\
\text { Col. } 7 \times \text { Col. } 8 \\
\text { L-Triangle } \\
\text { Entries }\end{array}$ \\
\hline 9 & $(1,1,1,1,1,1,1,1,1)$ & 1 & 362,880 & 1 & 362,880 & 362,880 & 1 & 362,880 & 362,880 \\
\hline 8 & $(2,1,1,1,1,1,1,1)$ & 1 & 181,440 & 8 & $1,451,520$ & $1,451,520$ & 9 & $13,063,680$ & $13,063,680$ \\
\hline \multirow[t]{2}{*}{7} & $(3,1,1,1,1,1,1)$ & 2 & 60,480 & 7 & 423,360 & $2,328,480$ & 36 & $15,240,960$ & $83,825,280$ \\
\hline & $(2,2,1,1,1,1,1)$ & & 90,720 & 21 & $1,905,120$ & & 36 & $68,584,320$ & \\
\hline \multirow[t]{3}{*}{6} & $(4,1,1,1,1,1)$ & 3 & 15,120 & 6 & 90,720 & $1,905,120$ & 84 & $7,620,480$ & $160,030,080$ \\
\hline & $(3,2,1,1,1,1)$ & & 30,240 & 30 & 907,200 & & 84 & $76,204,800$ & \\
\hline & $(2,2,2,1,1,1)$ & & 45,360 & 20 & 907,200 & & 84 & $76,204,800$ & \\
\hline \multirow[t]{5}{*}{5} & $(5,1,1,1,1)$ & 5 & 3,024 & 5 & 15,120 & 834,120 & 126 & $1,905,120$ & $105,099,120$ \\
\hline & $(4,2,1,1,1)$ & & 7,560 & 20 & 151,200 & & 126 & $19,051,200$ & \\
\hline & $(3,3,1,1,1)$ & & 10,080 & 10 & 100,800 & & 126 & $12,700,800$ & \\
\hline & $(3,2,2,1,1)$ & & 15,120 & 30 & 453,600 & & 126 & $57,153,600$ & \\
\hline & $(2,2,2,2,1)$ & & 22,680 & 5 & 113,400 & & 126 & $14,288,400$ & \\
\hline \multirow[t]{6}{*}{4} & $(6,1,1,1)$ & 6 & 504 & 4 & 2,016 & 186,480 & 126 & 254,016 & $23,496,480$ \\
\hline & $(5,2,1,1)$ & & 1,512 & 12 & 18,144 & & 126 & $2,286,144$ & \\
\hline & $(4,3,1,1)$ & & 2,520 & 12 & 30,240 & & 126 & $3,810,240$ & \\
\hline & $(4,2,2,1)$ & & 3,780 & 12 & 45,360 & & 126 & $5,715,360$ & \\
\hline & $(3,3,2,1)$ & & 5,040 & 12 & 60,480 & & 126 & $7,620,480$ & \\
\hline & $(3,2,2,2)$ & & 7,560 & 4 & 30,240 & & 126 & $3,810,240$ & \\
\hline \multirow[t]{7}{*}{3} & $(7,1,1)$ & 7 & 72 & 3 & 216 & 18,150 & 84 & 18,144 & $1,524,600$ \\
\hline & $(6,2,1)$ & & 252 & 6 & 1,512 & & 84 & 127,008 & \\
\hline & $(5,3,1)$ & & 504 & 6 & 3,024 & & 84 & 254,016 & \\
\hline & $(5,2,2)$ & & 756 & 3 & 2,268 & & 84 & 190,512 & \\
\hline & $(4,4,1)$ & & 630 & 3 & 1,890 & & 84 & 158,760 & \\
\hline & $(4,3,2)$ & & 1,260 & 6 & 7,560 & & 84 & 635,040 & \\
\hline & $(3,3,3)$ & & 1,680 & 1 & 1,680 & & 84 & 141,120 & \\
\hline \multirow[t]{4}{*}{2} & $(8,1)$ & 4 & 9 & 2 & 18 & 510 & 36 & 648 & 18,360 \\
\hline & $(7,2)$ & & 36 & 2 & 72 & & 36 & 2,592 & \\
\hline & $(6,3)$ & & 84 & 2 & 168 & & 36 & 6,048 & \\
\hline & $(5,4)$ & & 126 & 2 & 252 & & 36 & 9,072 & \\
\hline 1 & (9) & 1 & 1 & 1 & 1 & 1 & 9 & 9 & 9 \\
\hline \multicolumn{2}{|c|}{ Column Sum } & 30 & 871,030 & 256 & $7,087,261$ & $7,087,261$ & & $387,420,489$ & $387,420,489$ \\
\hline
\end{tabular}


TABLE 2: $S(n, w):$ Stirling Numbers of the second kind (matrix $\mathcal{M}_{2}$ )

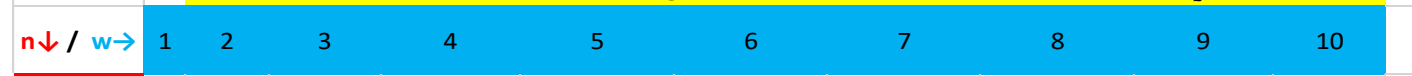

Row sums

Bell Numbers

(Series A000110)

\begin{tabular}{|c|}
\hline 1 \\
\hline 2 \\
\hline 15 \\
\hline 52 \\
\hline 203 \\
\hline 877 \\
\hline 4140 \\
\hline 21147 \\
\hline 115975 \\
\hline Row sums \\
\hline$\Sigma w !$ \\
\hline
\end{tabular}

\begin{tabular}{|c|c|c|c|}
\hline & & & \\
\hline 1 & & & \\
\hline 10 & 1 & & \\
\hline 65 & 15 & 1 & \\
\hline 350 & 140 & 21 \\
\hline 1701 & 1050 & 266 \\
\hline 7770 & 6951 & 2646 \\
\hline 34105 & 42525 & 22827 \\
\hline
\end{tabular}

TABLE 3: Factorials: w! (matrix $\mathcal{M}_{3}$ )

\begin{tabular}{|c|c|c|c|}
\hline & & & \\
\hline & & & \\
\hline & & & \\
\hline & & & \\
\hline 1 & & & \\
\hline 28 & 1 & & \\
\hline 462 & 36 & 1 & \\
\hline 5880 & 750 & 45 & 1 \\
\hline
\end{tabular}

8

9

10

\begin{tabular}{|c|r|r|r}
\hline 1 & 1 & & \\
\hline 2 & 1 & 2 & \\
\hline 3 & 1 & 2 & \\
\hline 4 & 1 & 2 & \\
\hline 5 & 1 & 2 & \\
6 & 1 & 2 & \\
7 & 1 & 2 & \\
\hline 8 & 1 & 2 & \\
\hline 9 & 1 & 2 & \\
10 & 1 & 2 & \\
\hline
\end{tabular}
4 5

\begin{tabular}{|}
\hline \\
\hline \\
\hline \\
\hline 5040 \\
\hline 5040 \\
\hline 5040 \\
\hline 5040 \\
\hline
\end{tabular}

4
5040

720 $5040 \quad 40320$ \begin{tabular}{|l|l|l|}
40320 & 362880 & 3628800
\end{tabular}

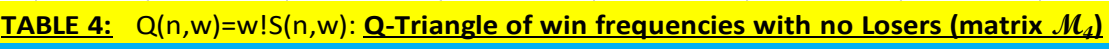

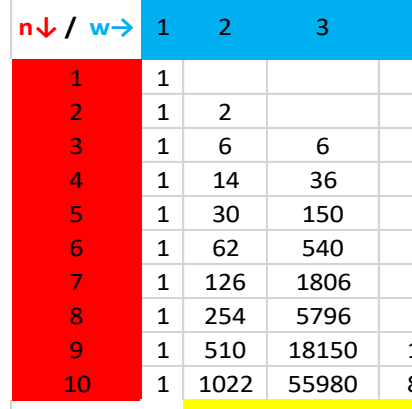

\begin{abstract}
4
\end{abstract}

\begin{abstract}
5
\end{abstract}
6

7

8

9

10

TABLE 5: Pascal's Triangle of binomial coefficients (zero column excluded) (matrix $\mathcal{M}_{5}$ )
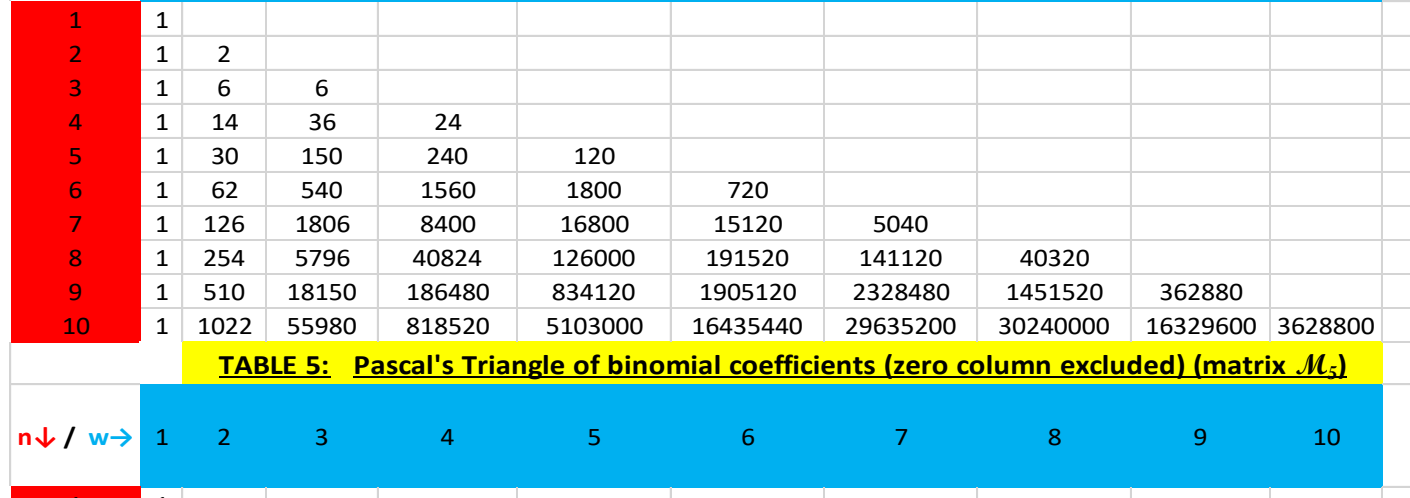

(Series A000670)

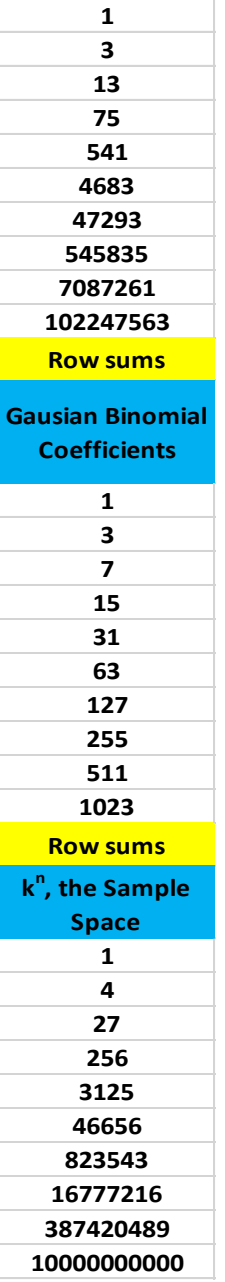



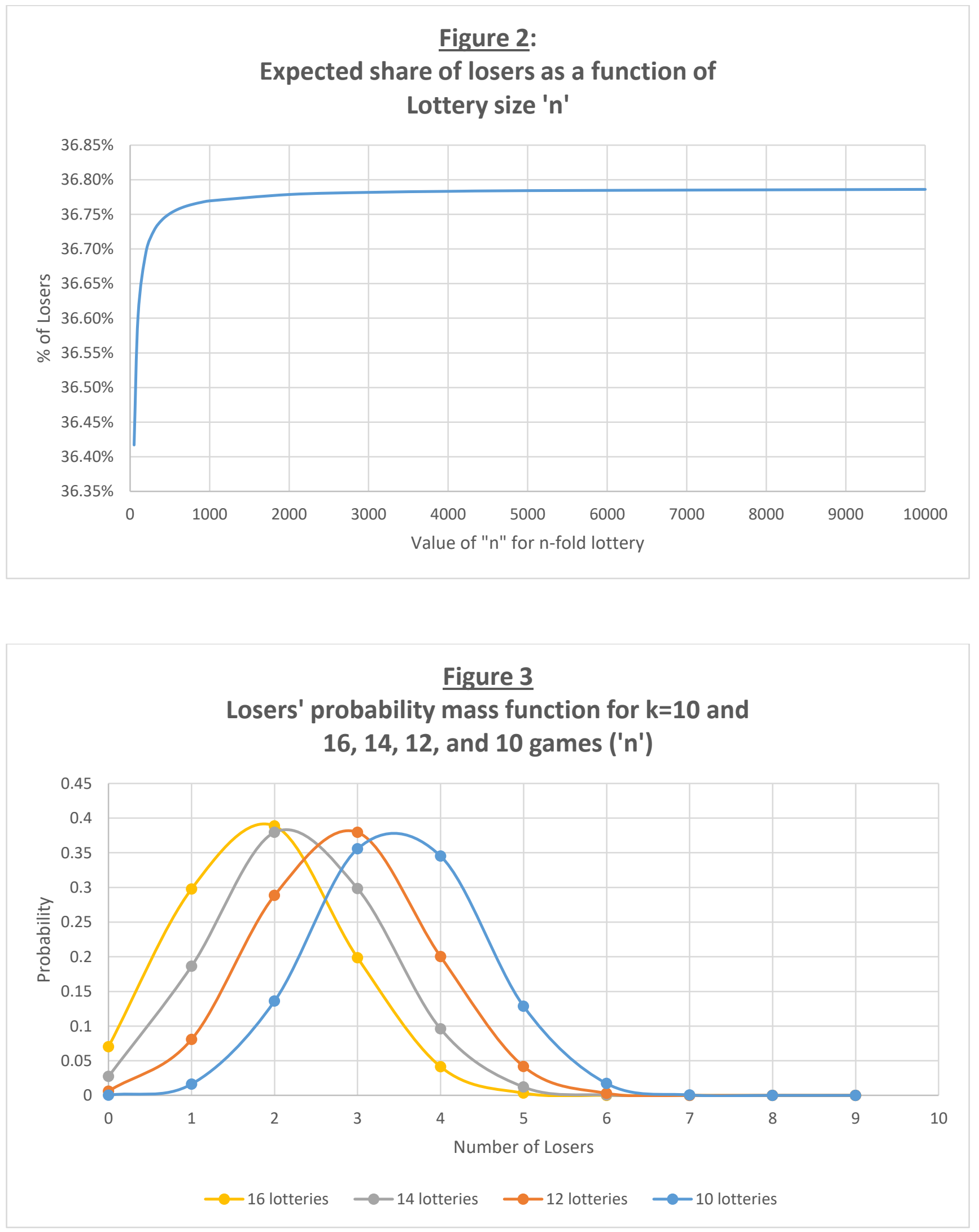


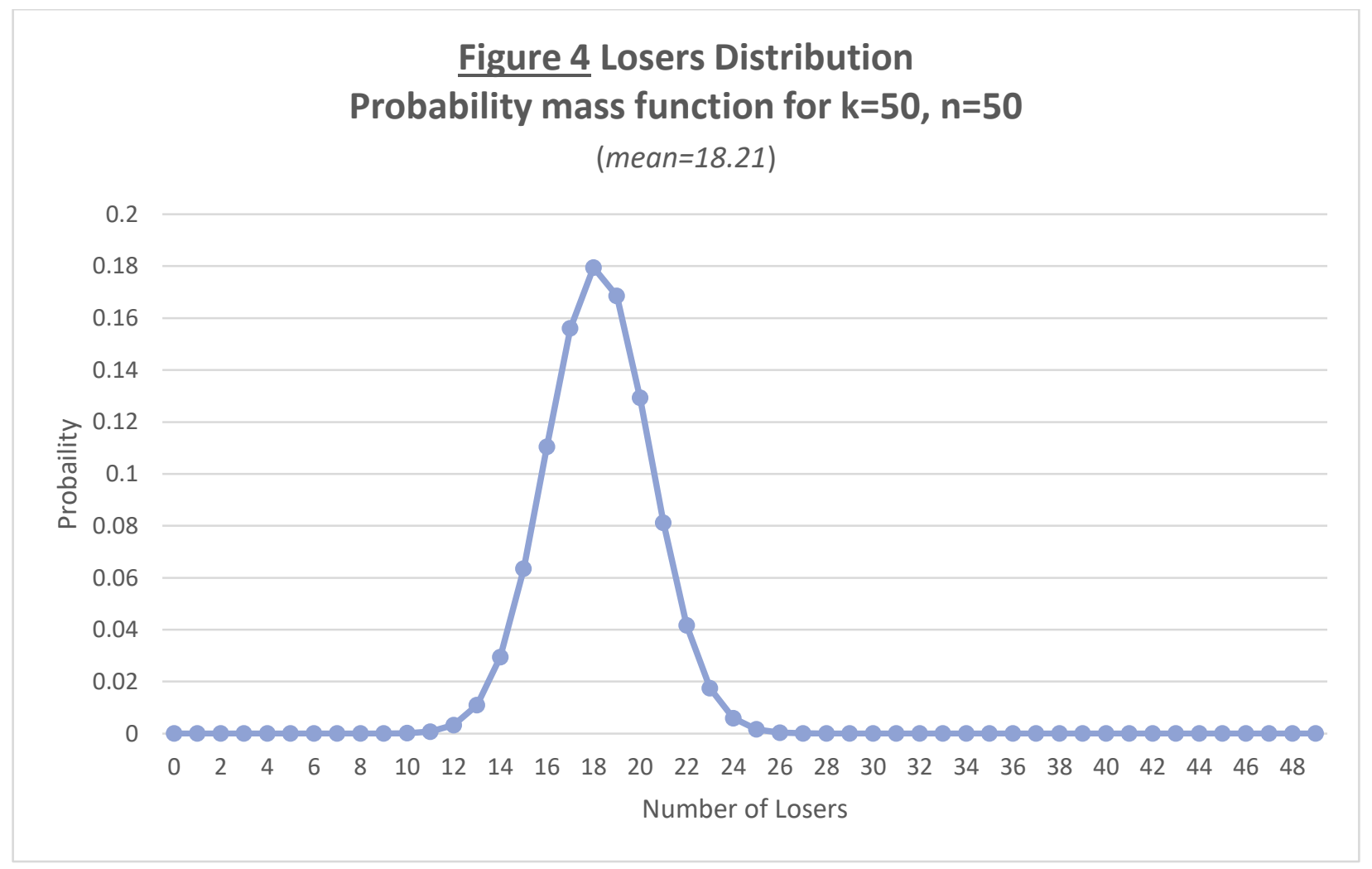


China's P2P lending meltdown Aug. 2018

$8-12 \%$ average returns to lenders vs. $3 \%$ in banks

World's biggest P2P market, about $\$ 180$ Billion loans outstanding

Now tighter regulations, liquidity crunch, scams, fraud, inexperienced investors

https://www.cnbc.com/video/2018/08/07/chinas-p2p-lending-meltdown.html

"Shadow-banking"

\$10 Trillion, 9\% is P2P lending. 50 Million registered users.

By August of 2018 4,500 P2P lending companies in China had failed, with 223 in the month of July, 2018 alone.

“China's Trillion-Dollar P2P Loan Industry Goes Bust" China Uncensored, (Aug. 22, 2018) https://www.youtube.com/watch?v=Inish4g6aGk

Ezubao defrauds 100 million investors P2P lenders of $\$ 7.6$ billion (NYTimes, Feb. 1, 2016)

https://www.nytimes.com/2016/02/02/business/dealbook/ezubao-china-fraud.html 